\title{
PERFORMANCE EVALUATION OF THERMOSYPHON INTEGRATED HEAT SINK FOR CPU COOLING
}

\author{
Shanmuga Sundaram Anandan*, Anirudh Bhaskaran \\ Department of Mechanical Engineering, Rajalakshmi Institute of Technology, Chennai, Tamil Nadu, India-600124
}

\begin{abstract}
An experimental study on Thermosyphon Integrated Heat Sink (TIHS) for CPU cooling has been carried out for both natural and forced convection to analyze the performance characteristics of the CPU cooling module (TIHS) at steady state condition. A thermal model based on the experimental values has been developed to study the thermal behavior of Thermosyphon Integrated Heat Sink during CPU cooling. The thermal model is employed to determine the actual heat transfer and the effectiveness of the CPU cooling module and compared it with the conventional cooling method and found that there is an appreciable improvement in the proposed CPU cooling module.
\end{abstract}

Keywords: Thermosyphon, Heat Sink, Effectiveness, CPU cooling

\section{Introduction}

A Thermosyphon is a two phase closed heat transfer system containing small amount of liquid in the evaporator section. The evaporator section is heated causing the liquid to vaporize and the vapor rises to the cold end of the tube to get condensed and thereby releasing its latent heat to the cooler medium. The condensate is returned to the evaporator section by gravity and the cycle repeats. The amount of heat that can be transported by these systems is normally several orders of magnitude greater than pure conduction through a solid metal as cited by Dunn et.al (1994). Since the latent heat of evaporation is large, considerable amount of heat can be transported from end to end with a very small temperature difference, hence such reliable heat transfer devices can be used in thermal management systems with limited space applications and other heat recovery systems.

The Thermosyphon Heat Sink integrated system works on both conduction and convection mechanism. The cooling module consisting of a parallel plate fin heat sink bonded to the array of thermosyphon tubes enhances the heat transfer within the system and with the surroundings through the larger heat transfer area, lower thermal resistance (between the source and the sink) and high effective thermal conductance of thermosyphon). The heat dissipated from the source is conducted through the heat sink base attached with a Thermal Interfacing Material (TIM) in order to reduce the contact thermal resistance between heater and the base. The heat from the base is transferred to heat sink and to the thermosyphons through conduction. The thermosyphon filled with R-134a as a refrigerant convects heat in to it and thereby causes the liquid to vaporize as it reaches its saturation temperature. The vapor carries the latent heat to the condenser kept inside the air duct with a tube axial fan mounted on it for forced convection. The relatively cooler medium at the condenser causes the vapor to condense and form film condensation which flows back to the

evaporator through the wall of the thermosyphon due to gravity. In order to enhance the heat transfer at the condenser, a ushaped longitudinal fin is bonded with the thermosyphons. This entire cycle repeats again and again to maintain the operating temperature of the CPU within the limit.

Tardy et.al (2009) developed a mathematical model for heat pipes in thermal storage. Finned heat pipes were used to transfer heat from the evaporator placed in an air stream flow to the condenser placed in a storage tank containing ice. The thermal behavior of heat pipes have been studied experimentally and analyzed under different conditions. H.Jouhara et.al (2008) developed a thermal model for a small diameter thermosyphon charged with water, FC-84, FC-77, FC3283 and an experimental investigation were carried out for water and the dielectric heat transfer liquids and the thermosyphon thermal performance have been presented.

\section{THERMAL RESISTANCE NETWORK MODELING}

\subsection{Calculation of Thermal Resistance}

The actual heat transfer for the Thermosyphon Heat Sink integration system can be found out by considering the thermal resistance shown in Figure1.

$$
\begin{aligned}
& \mathrm{R}_{\text {tot }}=\frac{1}{\mathrm{R}_{\mathrm{HB}}+\mathrm{R}_{\mathrm{BS}}+\mathrm{R}_{\mathrm{HS}}+\mathrm{R}_{\mathrm{TF}}+\mathrm{R}_{\mathrm{FA}}+R^{*}}
\end{aligned}
$$

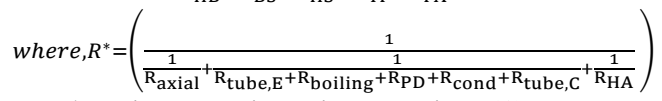

The thermal resistance given in Equation (1) represents the total thermal resistance across the heat sink, thermosyphon and the Ushaped longitudinal fin. The explanation of the thermal resistance parameters are given in Table 1.

\footnotetext{
*Corresponding author.Email:speakdrss@gmail.com
} 


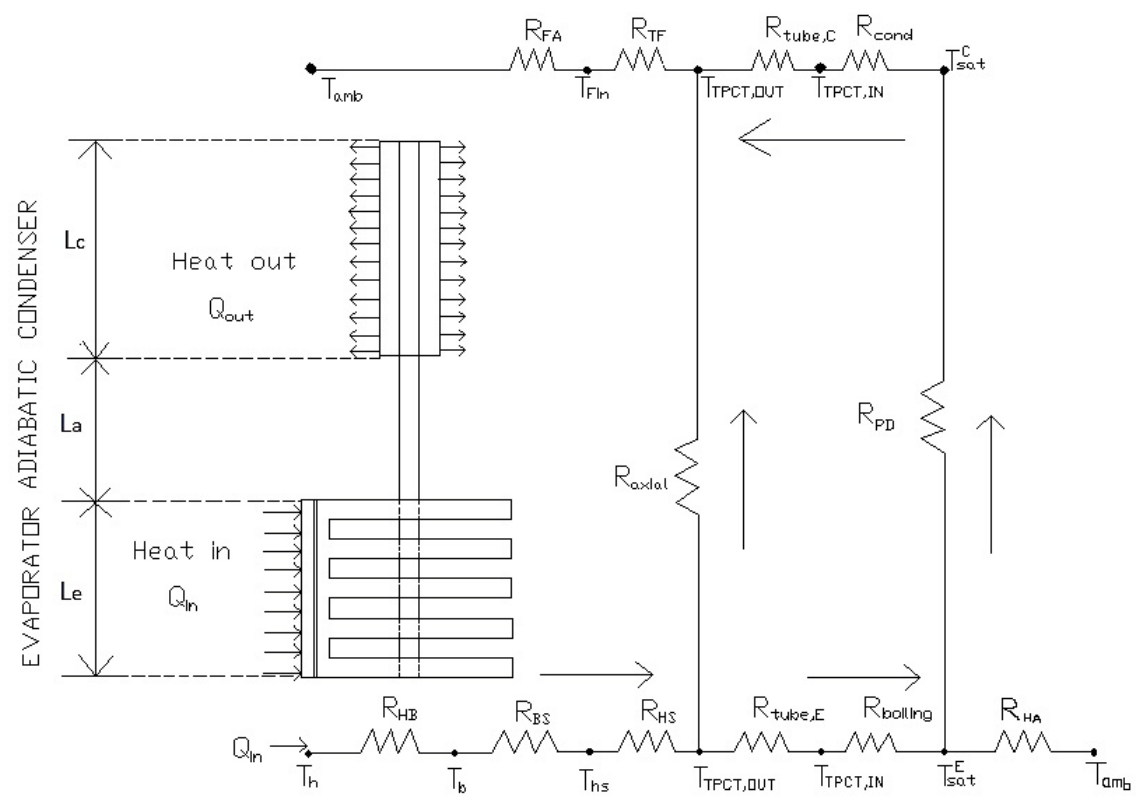

Fig. 1 Thermal resistance network of the Thermosyphon Heat Sink integrated system

Table.1 Thermal resistance equations of the THSIT

\begin{tabular}{|c|c|c|}
\hline S.no & Thermal Resistance & Equations \\
\hline 1 & Heater to base conduction (TIM) resistance & \\
\hline 2 & Base to Heat sink conduction resistance & \\
\hline 3 & Parallel plate fin Heat Sink conduction resistance & \\
\hline 4 & TPCT tube radial resistance at evaporator section & \\
\hline 5 & Evaporative boiling convective resistance & \\
\hline 6 & $\begin{array}{l}\text { Heat sink to ambient convective resistance at evaporator } \\
\text { section }\end{array}$ & \\
\hline 7 & TPCT tube axial resistance & \\
\hline 8 & $\begin{array}{l}\text { Resistance due to pressure drop from evaporator to } \\
\text { condenser section }\end{array}$ & \\
\hline 9 & Film condensation resistance at condenser section & \\
\hline 10 & TPCT tube radial resistance at condenser section & \\
\hline 11 & U-shaped longitudinal fin conduction resistance & \\
\hline 12 & $\begin{array}{l}\text { Fin to ambient convective resistance at condenser } \\
\text { section }\end{array}$ & \\
\hline
\end{tabular}

\subsubsection{Heat Transfer within the Thermosyphon}

The heat transfer taking place within the thermosyphon can be described by calculating the convective heat transfer coefficient for boiling as provided by Imura et al. (1972)

$$
h_{\text {evap }}=0.32 q_{\mathrm{e}}^{0.4} \times\left\{\frac{\rho_{1}^{0.65} k_{1}^{0.3} c_{p 1}^{0.7} g^{0.2}}{\rho_{\mathrm{g}}^{0.25} h_{\mathrm{fg}}^{0.4} \mu_{1}^{0.1}}\right\} \times\left(\frac{\mathrm{P}}{\mathrm{P}_{\mathrm{air}}}\right)^{0.3}
$$


Thermal resistance of the evaporative section is given as

$\mathbf{R}_{\text {boiling }}=\frac{1}{h_{\text {evap }} \times A_{\text {evap,int }}}=\frac{1}{h_{\text {evap }} \pi D_{\text {int }} \mathbf{L}_{\text {e }} N}$

Heat transfer within thermosyphon at the condenser section can be described by calculating the convective heat transfer coefficient due to film condensation as proposed by Nusselt (2005)

$h_{\text {cond }}=0.943\left\{\frac{\rho_{1} \mathrm{gk}_{1}^{3}\left(\rho_{1}-\rho_{\mathrm{v}}\right)\left[\mathrm{h}_{\mathrm{fg}}+0.68 \mathrm{C}_{\mathrm{pl}}\left(\mathrm{T}_{\mathrm{sat}}-\mathrm{T}_{\mathrm{w}}\right)\right]}{\mu_{1} \mathrm{~L}_{\mathrm{c}}\left(\mathrm{T}_{\mathrm{sat}}-\mathrm{T}_{\mathrm{w}}\right)}\right\}^{0.25}$

Thermal resistance of the condenser section is given as

$\mathbf{R}_{\text {cond }}=\frac{1}{h_{\text {cond }} \times A_{\text {cond,int }}}=\frac{1}{h_{\text {cond }} \pi D_{\text {int }} L_{c} N}$

The resistance due to the pressure drop of the vapor as it flows from evaporator to condenser is given as

$\mathbf{R}_{\mathbf{P D}}=\frac{\mathbf{T}_{\mathbf{v}}^{\mathrm{E}}-\mathbf{T}_{\mathbf{v}}^{\mathrm{C}}}{\mathbf{Q}_{\text {latent }}}$

\subsubsection{Thermosyphon wall thermal resistances}

Thermal resistance across the thickness of the thermosyphon can be calculated as

$\mathbf{R}_{\text {tube, } \mathrm{E}}=\frac{\ln \left(\mathrm{r}_{\text {tube,ext }} / \mathbf{r}_{\text {tube,int }}\right)}{2 \pi \mathbf{k}_{\text {tube }} \mathbf{L}_{\mathbf{e}}}$

$\mathbf{R}_{\text {tube, } \mathrm{C}}=\frac{\ln \left(\mathrm{r}_{\text {tube,ext }} / \mathbf{r}_{\text {tube,int }}\right)}{2 \pi \mathbf{k}_{\text {tube }} \mathbf{L}_{\mathrm{C}}}$

Thermal resistance along the axial length of the thermosyphon can be calculated as

$\mathbf{R}_{\text {axial }}=\frac{0.5 \mathbf{L}_{\mathrm{e}}+\mathbf{L}_{\mathrm{a}}+0.5 \mathbf{L}_{\mathrm{c}}}{\mathbf{k}_{\text {tube }} A_{\mathrm{cs}}}$

\subsubsection{Thermal Resistance of the Heat Sink}

Thermal resistance of the heat sink proceeds from the contact resistance between the heat source and the base plate at its interface. A thermal pad (T-250) as a Thermal Interfacing Material (TIM) of thickness $0.25 \mathrm{~mm}$ and thermal conductivity of $1 \mathrm{Wm}^{-10} \mathrm{C}^{-1}$ is attached between heat source and base plate in order to reduce the contact thermal resistance occurring at the interface. TIM has its ability to change its physical characteristics when it reaches the case operating temperature by filling the interfacial air gaps and surface voids in the base plate and heater surface.

$\mathbf{R}_{\mathrm{HB}}=\frac{\mathbf{t}_{\mathrm{TP}}}{\mathbf{k}_{\mathrm{TP}} \mathbf{A}_{\mathrm{TP}}}$

temperature is equal to the outside evaporator temperature.

\section{EXPERIMENTAL SETUP AND PROCEDURE}

The experimental setup of the cooling module consists of three sections namely: 1) Evaporator 2) Adiabatic and 3) Condenser as shown in Figure2. The evaporator section consists of the heat sink with 24 parallel plate fins each of $100 \times 100 \mathrm{~mm} 2$ area and $0.8 \mathrm{~mm}$ thickness bonded to a base plate of $100 \times 100 \mathrm{~mm} 2$ area and $6 \mathrm{~mm}$ thickness made of copper. A plate heater acts as a heat source of
Thermal resistance between the base and the heat sink is given as

$\mathrm{R}_{\mathrm{BS}}=\frac{\mathrm{L}_{\mathrm{b}}}{\mathrm{k}_{\mathrm{b}} \mathrm{A}_{\mathrm{b}}}$

Thermal resistance across the heat sink can be described as

$\mathbf{R}_{\mathrm{HS}}=\frac{1}{\mathrm{~h}\left(\mathrm{~A}_{\mathrm{b}}+\mathbf{N}_{\mathrm{f}} \eta_{\mathrm{f}} \mathbf{A}_{\mathrm{f}}\right)}$

\subsubsection{Fin-air Thermal Resistance}

The parallel plate fins and the u-shaped longitudinal fins exists at the evaporator and condenser sections respectively and the heat transfer coefficient as proposed by Brigg's and young (1963)

$h_{\text {air }}=\frac{k_{\text {air }}}{D_{\text {air }}} \times 0.1378 \times \operatorname{Re}_{\text {air }}^{0.718} \operatorname{Pr}_{\text {air }}^{0.333}\left(\frac{S_{\mathrm{f}}}{L_{\mathrm{f}}}\right)^{0.296}$

Thermal resistance between the air and the fins at the evaporator and condenser section is given as

$\mathbf{R}_{\mathrm{FA}}=\frac{1}{\mathrm{~h}_{\mathrm{air}} \mathbf{N}_{\mathrm{f}} \eta_{\mathrm{f}} \mathbf{A}_{\mathrm{f}}}=\mathbf{R}_{\mathrm{HA}}$

\subsubsection{Calculation of Heat Transfer rate and Effectiveness of the system}

Actual heat transfer rate includes the latent heat received from the condensing vapor and the sensible heat from the TPCT.

$\mathbf{Q}_{\text {latent }}=\frac{\mathbf{T}_{\mathrm{v}}^{\mathrm{E}}-\mathrm{T}_{\mathrm{v}}^{\mathrm{C}}}{\mathbf{R}_{\mathrm{PD}}}$

Sensible heat transfer due to the change in surface temperature of TPCT

$\mathbf{Q}_{\text {sensible }}=\frac{T_{\mathbf{b}}-T_{\infty}}{\mathbf{R}_{\text {tot }}-\mathbf{R}_{\mathrm{HB}}-\mathbf{R}_{\text {boiling }}-\mathbf{R}_{\mathrm{PD}}-\mathbf{R}_{\text {cond }}}$

Actual heat transfer rate is given by,

$$
\begin{aligned}
\mathbf{Q}_{\text {actual }} & =\mathbf{Q}_{\text {latent }}+\mathbf{Q}_{\text {sensible }} \\
& =\frac{\mathbf{T}_{\mathrm{v}}^{\mathrm{E}}-\mathbf{T}_{\mathrm{v}}^{\mathrm{C}}}{\mathbf{R}_{\mathrm{PD}}}+\frac{\mathbf{T}_{\mathbf{b}}-\mathbf{T}_{\infty}}{\mathbf{R}_{\text {tot }}-\mathbf{R}_{\mathrm{HB}}-\mathbf{R}_{\text {boiling }}-\mathbf{R}_{\mathrm{PD}}-\mathbf{R}_{\text {cond }}}
\end{aligned}
$$

Effectiveness of the system is given as,

$\varepsilon=\frac{\text { Actual heat transfer }}{\text { Maximum heat transfer }}$

Maximum heat transfer is attained when the condenser

400W capacity is attached to the base plate by means of a Thermal Interfacing Material $\mathrm{T}-250$ of thickness $0.25 \mathrm{~mm}$ with a thermal conductivity of $1 \mathrm{~W} / \mathrm{m}^{\circ} \mathrm{C}$ and a thermal resistance of $0.49{ }^{\circ} \mathrm{C} / \mathrm{W}$. Six TPCT of $9.52 \mathrm{~mm}$ outer diameter and $7.92 \mathrm{~mm}$ inner diameter and having a thickness of $0.8 \mathrm{~mm}$ is bonded along with the parallel plate fins in a staggered arrangement. This evaporator section has a chosen length of $100 \mathrm{~mm}$. The adiabatic section has a chosen length of $50 \mathrm{~mm}$ and the condenser section having a length of $150 \mathrm{~mm}$ is fitted with the longitudinal u-shaped fins made of copper and bonded along with the TPCT. 
Each TPCT is bonded with 12 fins of $0.8 \mathrm{~mm}$ thickness and height of $8.3 \mathrm{~mm}$ for the entire length of the condenser section. Thereby, the condenser section consists of 72 fins in total for 6 TPCT's. The condenser section is equipped with a cylindrical duct and a tube axial fan mounted on it to provide the forced convection condition. The tube axial fan has a volumetric flow rate of 127 CFM at 2000rpm.

The experiments were conducted for both natural convection and forced convection in which the later was carried out for the volumetric flow rates of 102 CFM, 115 CFM and 127 CFM for various heat inputs (40-70W). The temperatures at the surface of the thermosyphon and the vapor temperatures at the corresponding sections have been measured by 26 K-type Chromel-Alumel Teflon coated thermocouples as shown in fig 3 and the readings were recorded by a data acquisition system. An air flow sensor was also incorporated to measure the flow rate of the air from the tube axial fan. The accuracy of the thermocouples was of $\pm 1.5^{\circ} \mathrm{C}$ up to $200^{\circ} \mathrm{C}$. The accuracy of air flow arrangement was $\pm 3 \%$ of full scale. The maximum possible error in measured quantities of temperature is calculated from the minimum values of the temperature measured and accuracy of the instrument. Therefore for an accuracy of $0.1^{0} \mathrm{C}$ of the instrument and $\pm 1.5^{\circ} \mathrm{C}$ for thermocouples, the calculated error is $0.414 \%$.

The temperatures at the heat sink were measured in such a way that the arithmetic averages of these values are taken as the mean base plate temperature $\mathrm{T}_{\text {base }}$. Ambient temperature is measured at one location in the test environment. During testing, the uniform spreading of heat along the surface of the base plate is validated (i.e) the maximum temperature difference between the three measurements is less than $10 \%$ of the average of the base plate temperature.

The average of each TPCT surface and vapour temperatures at evaporator and condenser section is taken for evaluating the performance of the system. The working fluid in the thermosyphon was R134a. All the tests were performed under steady state conditions.

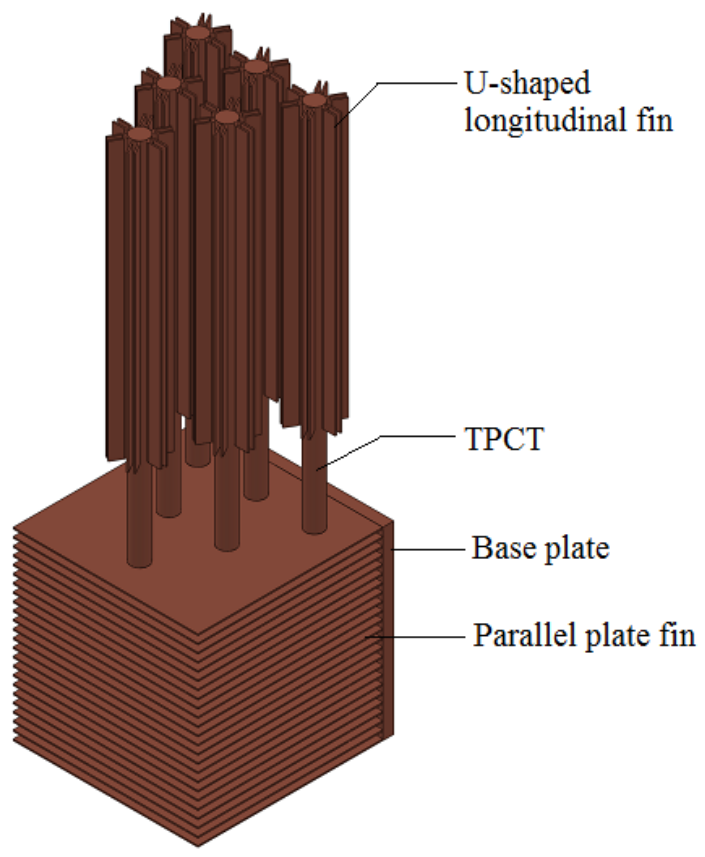

Fig. 2 Experimental Model of Thermosyphon Heat Sink Integrated System

\section{RESULTS AND DISCUSSION}

The aforementioned equations in the thermal resistance network modeling section were used to calculate the actual heat transfer rate and effectiveness of the system with the average experimental values. The Figure3 shows the graphical variation of total thermal resistance versus the heat input for natural convection and forced convection for air flow rate of 102, 115, 127 CFM respectively. The total thermal resistance of the system for natural convection varies from $0.32 \mathrm{~K} / \mathrm{W}$ to $0.33 \mathrm{~K} / \mathrm{W}$ for the corresponding heat inputs. The total thermal resistance of the system for forced convection for the air flow rates of $102,115,127$ CFM varies from $0.227 \mathrm{~K} / \mathrm{W}$ to $0.233 \mathrm{~K} / \mathrm{W}$. The lowest thermal resistance was found to be at 127CFM air flow rate at 70W heat input. This shows that when the heat input is increased, the total thermal resistance of the system decreases by an insignificant amount.

Similarly, the Figure4 shows the graphical variation of effectiveness of the system versus the heat input for natural and forced convection for an air flow rate of 102,115,127 CFM respectively. The effectiveness of the system for natural convection varies from 0.69 to 0.636 for the corresponding values of heat inputs. The effectiveness of the system for forced convection for air flow rates of 102,115 and 127 CFM varies from 0.803 to 0.878 for corresponding heat inputs. The maximum effectiveness of the system was to be 0.878 at $127 \mathrm{CFm}$ and $40 \mathrm{~W}$ of heat input. This shows that the system's performance will be maximum for forced convection at 127CFM air flow rate and the corresponding thermal resistance of the system is $0.23 \mathrm{~K} / \mathrm{W}$. The cooling module will dissipate maximum amount of heat from the condenser to the surroundings when the air flow rate along the condenser is maximum.

Therefore, the performance evaluation shows a satisfactory result of appreciable increase in the system performance in the form of effectiveness and found to be $7 \%$ increase for natural convection when compared with the conventional cooling method and $25 \%$ increase for forced convection. A quantitative comparison on the conventional cooling method and the present cooling method is given in table 2. The design specifications of the conventional cooling module are of a Pentium IV desktop CPU whose tube axial fan has a volumetric flow rate of 8CFM [8]. Moreover, the experimental cooling module presented is a scaled up model for experimental purpose and hence it required higher CFM tube axial fan.

\section{CONCLUSION}

The thermal modeling of Thermosyphon Heat Sink Integrated system for CPU cooling have been modeled, presented and discussed. An experimental setup has been constructed and tested at steady state condition from which the experimental values have been used to determine the effectiveness of the system. The cooling module proved to be fairly better than the conventional cooling module as discussed previously. The results obtained from experimental studies indicated that as the heat input value increases, both the thermal resistance and effectiveness decreases in a very small amount. Thus in order to enhance the performance of the cooling module, attention has to be taken on dominating individual resistances that constitute the $\mathrm{R}_{\mathrm{tot}}$, such as the resistance of power input to the evaporator and the resistance on the condenser side. 


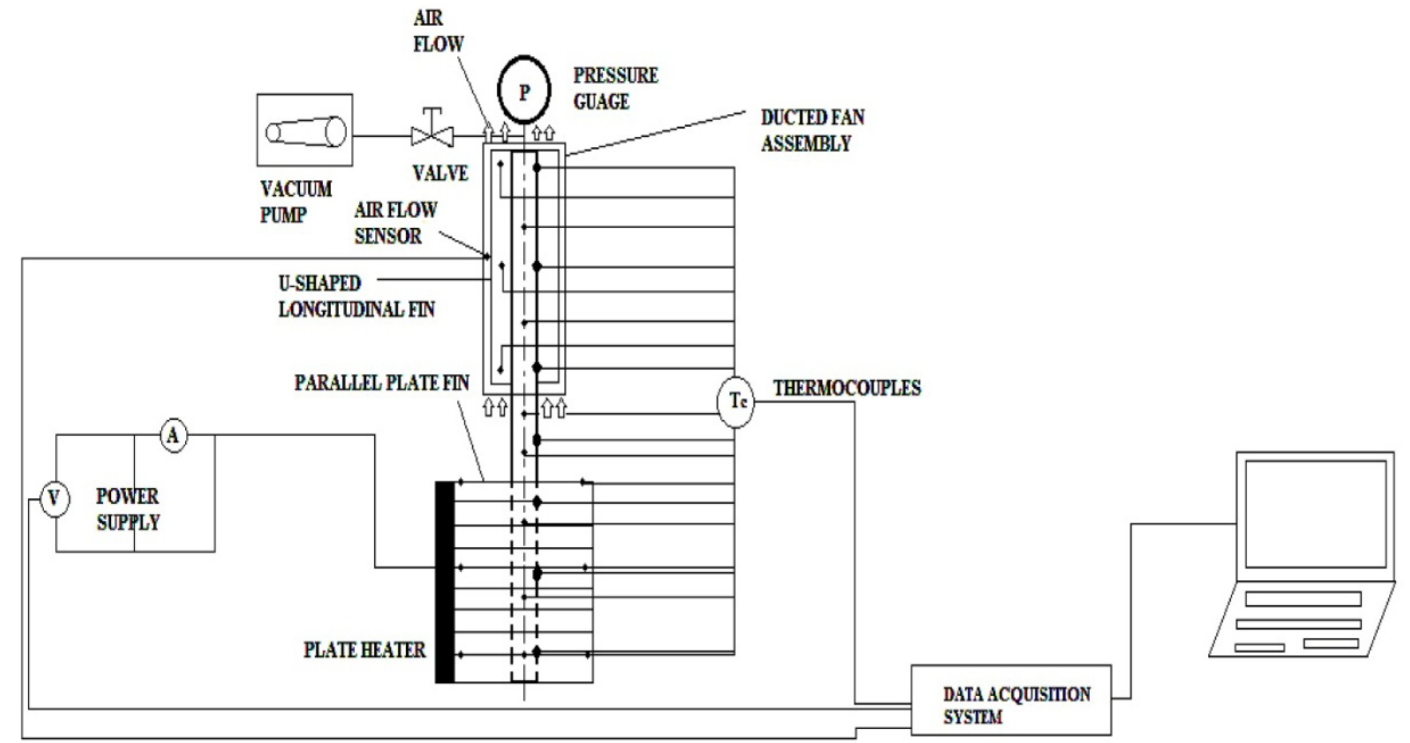

Fig. 3 Experimental setup of Thermosyphon Heat Sink Integrated System with 1 TPCT
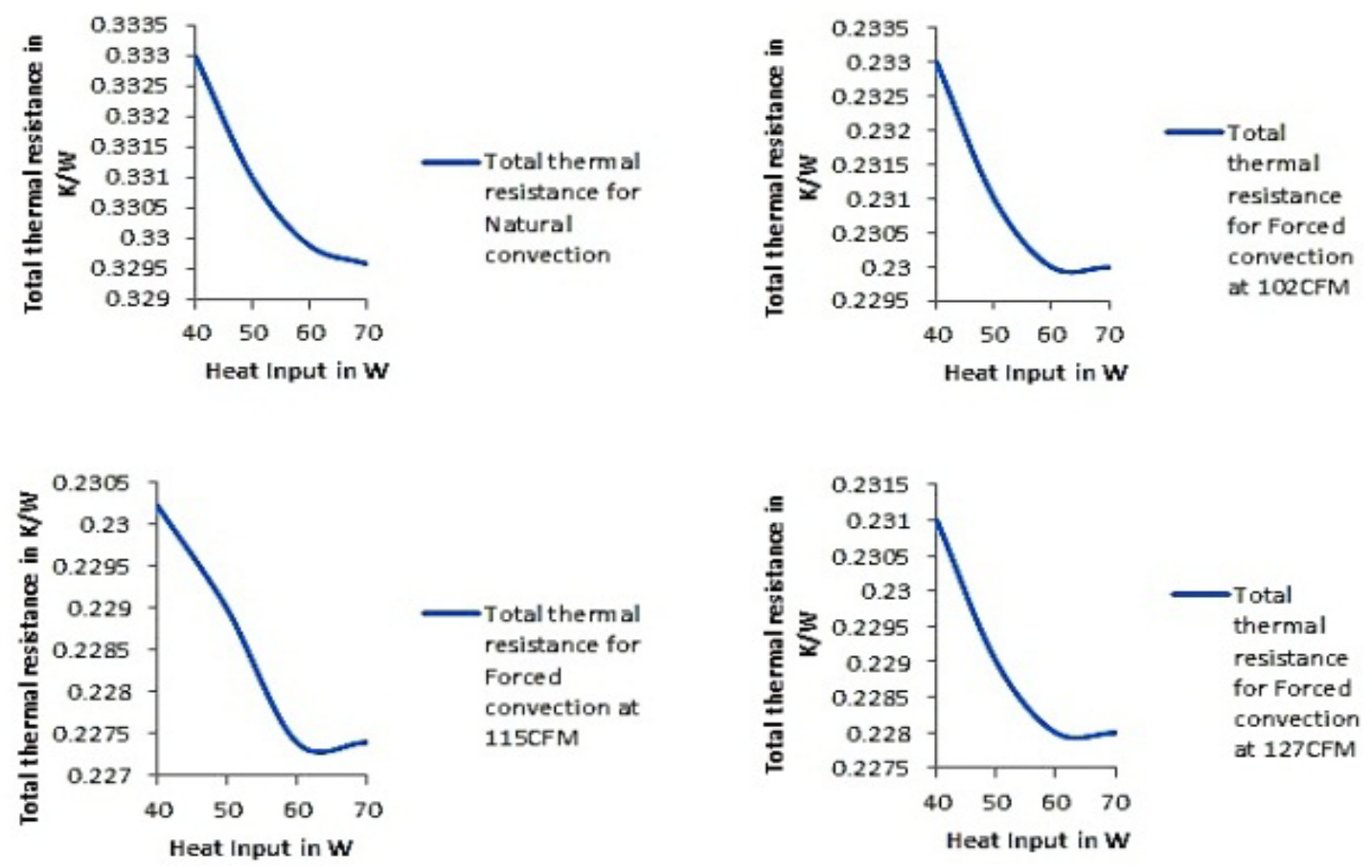

Fig. 4 Total thermal resistance of the system for various heat inputs

Table. 2 Comparison of performance evaluation results between the conventional and the present model

\begin{tabular}{|c|c|c|c|c|c|}
\hline \multirow{3}{*}{ System } & $\begin{array}{l}\text { Conventional } \\
\text { Heat Sink } \\
\text { Effectiveness }\end{array}$ & \multicolumn{4}{|c|}{ Thermosyphon Heat Sink Integrated System } \\
\hline & Forced & Natural Convection & \multicolumn{3}{|c|}{ Forced Convection, CFM } \\
\hline & & & 127 & 115 & 102 \\
\hline 40 & 0.65 & 0.69 & 0.878 & 0.874 & 0.87 \\
\hline 50 & 0.62 & 0.652 & 0.869 & 0.875 & 0.864 \\
\hline 60 & 0.59 & 0.641 & 0.832 & 0.826 & 0.825 \\
\hline 70 & 0.56 & 0.636 & 0.812 & 0.81 & 0.803 \\
\hline
\end{tabular}



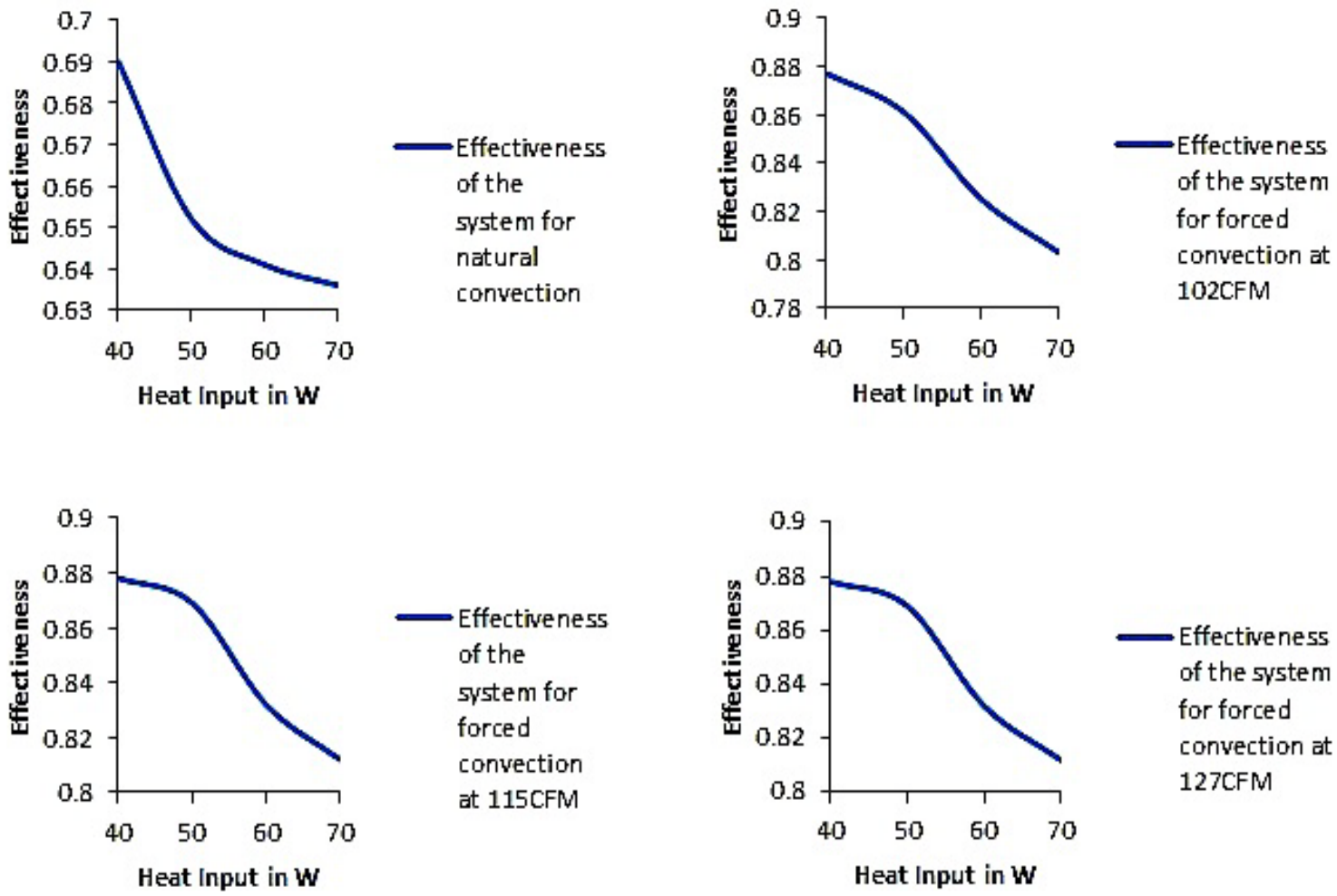

Fig. 5 Effectiveness of the system for various heat inputs

\section{NOMENCLATURE}

$\mathrm{A}, \mathrm{A}_{\mathrm{cs}}$

$A_{b}$

$\mathrm{A}_{\mathrm{TP}}$

$\mathrm{C}_{\mathrm{pl}}$

$\mathrm{h}$

$\mathrm{h}_{\mathrm{fg}}$

$\mathrm{k}$

$L_{a}$

$\mathrm{L}_{\mathrm{b}}$

$\mathrm{L}_{\mathrm{c}}$

$\mathrm{L}_{\mathrm{e}}$

$\mathrm{N}$

$\mathrm{N}_{\mathrm{f}}$

$\mathrm{P}$

$\mathrm{q}_{\mathrm{e}}$

$\mathrm{Q}_{\text {in }}$

Qout

$\mathrm{R}_{\text {axial }}$

$\mathrm{R}_{\text {boiling }}$

$\mathrm{R}_{\mathrm{BS}}$

$\mathrm{R}_{\text {cond }}$

$\mathrm{R}_{\mathrm{FA}}$

$\mathrm{R}_{\mathrm{HB}}$

$\mathrm{R}_{\mathrm{HS}}$

$\mathrm{R}_{\mathrm{TF}}$

$\mathrm{R}_{\mathrm{tot}}$

Cross Sectional area of TPCT, $\mathrm{m}^{2}$

Area of base plate, $\mathrm{m}^{2}$

Area of Thermal Pad, $\mathrm{m}^{2}$

Specific Heat, $\mathrm{Jkg}^{-1} \mathrm{~K}^{-1}$

Heat transfer Coefficient, $\mathrm{Wm}^{-2} \mathrm{~K}^{-1}$

Latent heat of vapourization, $\mathrm{J} / \mathrm{kg}$

Thermal Conductivity, $\mathrm{Wm}^{-1} \mathrm{~K}^{-1}$

Adiabatic length, $m$

Length of base plate, $\mathrm{m}$

Condenser length, $\mathrm{m}$

Evaporator length, $\mathrm{m}$

Number of TPCT

Number of fins

Saturation Pressure, bar

Heat Flux, W/m ${ }^{2}$

Heat Input, $\mathrm{W}$

Heat Output, W

Axial resistance of TPCT, K/W

Evaporator Boiling Resistance, K/W

Base to Sink Resistance, K/W

Film Condensation Resistance, K/W

Fin to air resistance, K/W

Heater to Base Resistance, K/W

Heat Sink Thermal Resistance, K/W

TPCT to fin resistance, $\mathrm{K} / \mathrm{W}$

Total thermal resistance, $\mathrm{K} / \mathrm{W}$
Effectiveness

of the

system for

natural

convection

Effectiveness

of the

system for

forced

convection

at $115 \mathrm{CFM}$
$\mathrm{R}_{\text {tube,C }}$

$\mathrm{R}_{\text {tube,E }}$

$\mathrm{S}_{\mathrm{f}}$

$\mathrm{T}_{\mathrm{b}}$

$\mathrm{T}_{\mathrm{v}}^{\mathrm{C}}$

$\mathrm{T}_{\mathrm{v}}^{\mathrm{E}}$

$\mathrm{T}_{\mathrm{h}}$

$\mathrm{T}_{\text {hs }}$

$\mathrm{T}_{\mathrm{TPCT}, \mathrm{in}}$

$\mathrm{T}_{\text {TPCT,out }}$

$\mathrm{T}_{\mathrm{amb}}, \mathrm{T}_{\infty}$

$\mathrm{T}_{\mathrm{w}}$

$\mathrm{T}_{\mathrm{f}}$

Greek Symbols

$\mu$

$\eta$

$\rho$

Subscripts

b

C,c,cond

E, e,evap

CS

TP
Condenser side tube Resistance, $\mathrm{K} / \mathrm{W}$ Evaporator side tube Resistance, K/W Fin pitch, $m$

Base Temperature, ${ }^{\circ} \mathrm{C}$

Condenser vapour temperature, ${ }^{\circ} \mathrm{C}$

Evaporator vapour Temperature, ${ }^{\circ} \mathrm{C}$

Heater Temperature, ${ }^{\circ} \mathrm{C}$

Heat Sink Temperature, ${ }^{\circ} \mathrm{C}$

TPCT inner wall Temperature, ${ }^{\circ} \mathrm{C}$

TPCT outer wall Temperature, ${ }^{\circ} \mathrm{C}$

Ambient Temperature, ${ }^{\circ} \mathrm{C}$

Tube wall temperature, ${ }^{\circ} \mathrm{C}$

Fin temperature, ${ }^{\circ} \mathrm{C}$ 


$\begin{array}{ll}\mathrm{f} & \text { fin } \\ \text { in } & \text { Input } \\ \text { out } & \text { Output } \\ \text { BS } & \text { Base to Sink } \\ \text { HB } & \text { Heater to Base } \\ \text { HS,hs } & \text { Heat Sink } \\ \text { FA } & \text { Fin to air } \\ \text { TF } & \text { TPCT to fin } \\ \text { tot } & \text { total } \\ \text { tube,E } & \text { Evaporator tube } \\ \text { tube,C } & \text { Condenser tube } \\ \text { sat } & \text { Saturation } \\ \text { TPCT,in } & \text { TPCT inner wall } \\ \text { TPCT,out } & \text { TPCT outer wall } \\ \text { w } & \text { wall } \\ \text { v } & \text { Vapour }\end{array}$

\section{Superscripts \\ E Evaporator}

C Condenser

$\begin{array}{ll}\text { Non Dimensional Numbers } \\ \operatorname{Re} & \text { Reynolds Number } \\ \mathrm{Pr} & \text { Prandtl Number }\end{array}$

\section{Abbreviations}

$\begin{array}{ll}\text { CFM } & \text { Cubic Feet per Minute } \\ \text { TIM } & \text { Thermal Interfacing Material } \\ \text { TPCT } & \text { Two Phase Closed Thermosyphon }\end{array}$

\section{ACKNOWLEDGEMENT}

We take immense pleasure to express our gratitude to the management of Rajalakshmi Institute of Technology for their cooperation and encouragement for the completion of this project. We would like to express our special gratitude and thanks to Dr.R.V.Seeniraj for extending his technical expertise in completing this project.

\section{REFERENCES}

Dunn, P \& D.A.Reay 1994, Heat pipes. $4^{\text {th }}$ ed., Pergamon.
F.Tardy, Samuel M.Sami, 2009, "Thermal analysis of heat pipes during thermal storage”, Applied Thermal Engineering 29,329-333. http://dx.doi.org/10.1016/j.applthermaleng.2008.02.037.

H.Jouhara, O.Martinet, A.J. Robinson,2010, "Experimental study of small diameter Thermosyphons charged with with water, FC-84, FC77 \& FC-3283”, Applied Thermal Engineering,30, issue2-3, 201-211. http://dx.doi.org/10.1016/j.applthermaleng.2009.08.007

Imura, H., Kusada, H., Oyata, J., Miyazaki, T.,and Sakamoto, N., 1972, "Heat Transfer in Two-PhaseClosed Thermosyphon", International Journal of Heat and Mass Transfer, 15(9), 1395-1707. http://dx.doi.org/10.1016/0017-9310(72)90098-1.

S. H. Noie, M. H. Kalaei, M. Khoshnoodi, 2005, “ Experimental investigation of boiling and condensation heat transfer of a two phase closed thermosyphon", International Journal of Engineering, 18(4),100-112.

http://www.sid.ir/En/VEWSSID/J_pdf/856200501A01.pdf.

Briggs, D.E and Young, E.H., 1963, "Convection heat transfer and pressure drop of air flowing across triangular pitch banks of finned tubes”, Chem Eng. Prog. Symp. Ser., Vol59, No.41, pp1-10

Aniruddha Pal and Yogendra Joshi ,2002, "Design and performance evaluation of a compact thermosyphon”, Components and Packaging Technologies, IEEE Transactions 25, PP 601-604.

DOI: $10.1109 /$ TCAPT.2002.807997

R.A.Wirtz, Weiming Chen, Ronghua Zhou, "Effect of flow by - pass on the performance of longitudinal fin heat sinks”, Journal of electronics packaging,Transactions of the ASME, vol.116, Sep 1994. http://dx.doi.org/10.1115/1.2905687

Ralph L. Webb, "Next Generation Devices for Electronic Cooling with Heat Rejection to Air". ASME J. Heat Transfer, Vol.127, 2005, 2-10 http://dx.doi.org/10.1115/1.1800512

Florio, Harnoi. A, "Combination technique for improving natural convection cooling in electronics", International journal of thermal sciences, vol 46,issue1,2007,pp:76-92

http://dx.doi.org/10.1016/j.ijthermalsci.2006.03.007 